\title{
Spatialities of the energy transition: Intensive sites making earth matter?
}

Olivier Labussière, Alain Nadaï

\section{Introduction}

"For at least the past decade, satellites have spotted white dots cropping up in the North Sea. If viewed from Earth's surface, you would see that these dots are actually wind turbines-huge arrays of towers rising from the sea and topped with electricity-generating rotors. But they're doing more than harvesting the wind. They appear to also be giving rise to sediment plumes"(1). The satellite image from Landsat 8-Open Land Imager makes visible a phenomenon that is otherwise hard to experience: the large-scale expansion of new energy technologies on the earth's surface. In this particular case, the 'London Array' offshore wind farm, located in the North Sea, just outside the mouth of the River Thames, spans more than $100 \mathrm{~km}^{2}$ and is flanked by two other offshore wind farms - one on the north and the other on the south. This Landsat image shows a spatial expansion that stretches far beyond a clear-cut wind power area. The tidal currents moving around the turbines' foundations generate clearly visible comet tails of suspended sediment. These 'plumes' of sediment make their way forward in the North Sea and raise fresh issues with respect to sandbanks and the migration of fish. It shows how renewable energies, in their spatial expansion, give rise to energy spatialities that are not bounded and may confront what we will name here "earth's forces" or "earth's matters". We mean by this term material or living cycles - such as ocean or air currents, climate or soils dynamics, animal migrations, etc. - which connect us to our large scale environment, pertain to the earth as a living envelope and, ultimately, point out at its geopolitics (our responsibility in answering to climate change issue, for instance). This, in turn, raises the issue of how to attend to these spatial interactions and account for their role and consequences amid the expansion of renewable energies.

In order to tackle this question, the paper proposes an alternative to existing, mostly quantitative, efforts to assess the spatial expansion of renewable energy technologies. These efforts used to attribute standard land areas to a given renewable energy technology 1 in order to calculate the share of land that may be covered by these technologies in the future (2), (3), (4), (5), (6). These works flesh out at different scales the idea previously assumed by authors like Walker (7) and Smil (8), (9), through the concept of 'power density';; for the latter, that renewable energy developments are highly land intensive. From a different angle, Scheidel and Sorman (10) suggest that the land rush associated with the global energy transition effectively contributes to the current phenomenon of land grabbing. Taken together, these approaches have made us aware of the ongoing and profound spatial 
restructuring associated with the expansion of renewable energies, whose various effects and qualitative implications remain however hard to describe.

To boost understanding in this field, this paper takes inspiration from relational thinking. As many authors have shown (11), (12), (13), (14), approaching space in a relational way goes beyond the idea of space as a container or a geometric form in which social life unfolds. A relational understanding conceives of space as material, active and contingent and shines a light on the processes and dynamics of emergence - in our case, the processes of development and deployment of technological innovations and the associated emergence of energy spatialities. STS scholars have devoted a lot of attention to the geographical materiality associated with the emergence of sociotechnical networks (15), (16), (17), (18). Nevertheless, this strand of analytical works has not addressed - in the same way that the quantitative approaches mentioned above point out - the 'criticality' and the political dimension of the issues that could result from scaling up and expanding new (energy) technologies, and the way in which this could end up confronting earth's forces. Such a gap calls for further exploration of the intersection between the relational dimension of technological change and the emerging concern of the earth's crisis (climate, ocean, soil, air, etc.).

In order to venture in this direction, this paper develops a cross-perspective between the work of Simondon on the genesis of the technical object (19) and that of Latour (20), (21) on the earth as a living assemblage whose 'critical zones' allow us to experiment with new entanglements between technological development and earth's untamed forces. These works allow us to tackle the relational character of contemporary energy spatialities while jointly addressing the scaling up of renewable energy technologies and their interactions with recent environmental concerns. The view that stems from this approach is that the process of technological innovation is relational, but some places, which Simondon calls hautlieux ('intensive sites'), prove to be highly relational in that they foster the apprenticeship about how a technology may suitably be adapted to earth's singular forces. Following Latour, such 'intensive sites' are like 'critical zones': places where it is possible to connect and experiment with innovative earth politics. The geographical expansion of renewable energy technologies proceeds with a relational process that attempts to deploy the innovative entanglements that have been stabilised at 'intensive sites' at new (which Simondon calls 'extensive') sites.

The first part presents our articulation of Latour's and Simondon's approaches. The second part draws on two case studies: the first one is about offshore wind power development in the North Sea (Germany) and the Western Channel (France), the second one about an onshore wind power development in the Narbonnaise (Southern France). Using qualitative methods (face to face interviews and participant observation), it analyses the processes' spatial intensities and their relation to extension. The third part of the paper proposes a critical 
appraisal of Simondon's notions and a characterisation of the relational criticality of renewable energies' geographical expansion.

\section{2. "Critical zone": turning the earth into a (geo)political notion}

One of the paper's goals is to develop propose a way of jointly seizing and analysing the intertwined spatial changes produced by the contemporary energy transition - in particular, those associated with the large-scale expansion of renewable energies. Such endeavour questions our capacity to overcome the inherited and modern figure of the earth - a globe, a physical whole - and find new figures that more finely bear witness of the earth crisis as situated processes of technological change (to fight climate change) in which earth forces matter. The paper goes ahead with this idea and examines two case studies in which the development of wind energy takes place in sites (in France and Germany) in which the reordering of the earth forces - as entangled in a living and changing membrane - is at stake.

The framing of the energy transition that resulted from the international scientific conference "Our Common Future under Climate Change" called for developing large scale technological solutions to fight climate change. While acknowledging climate change as a (stabilised) scientific fact and the $2{ }^{\circ} \mathrm{C}$ threshold as a desirable target, this statement confirmed that the time of action has arrived and directed attention to big "scalable" - albeit contested - solutions as the only way forward. Straightforward in appearance, with the scale of the solutions appearing to be congruent with that of the problem, this approach to the energy transition may fall short of its ambitions for several reasons. In framing certain solutions (and not others) as (readily) "scalable", it ends up endowing the "big vs small" distinction with a natural and strategic character and enticing us to believe that only such solutions constitute the rational answer to the climate issue. Restricting our attention to such contested solutions - indeed, carbon capture and storage (CCS), nuclear and even big-scale (onshore and offshore) wind power are contested (22) - and calling on the social sciences to alleviate the barriers to their development is misleading. It reduces contestation to (local) opposition to project development without acknowledging that there are multiple ways of scaling up, each of which has distinct spatial, political, social, economic and environmental implications, and that opposition may as well target the politics of energy transition enshrined in certain ways of scaling up (23). In any event, energy technologies, just like any other technology, not only have an impact but also reshape the world around them (society, environment) in order to come into existence (15), (19).

The way of consolidating quantified visions that is most common in policy processes is to naturalise the resource - for example, to reduce it to its physical dimension, like a kinetic flow, solar radiation or a water stream - in order to quantify both a 'deposit' and an associated 
'technological potential'. Thus, there is a strong coherence between the way of framing the problem - attaching it to the notion of the earth as a constituted whole - and that of framing and scaling up the solutions. Stated differently, envisioning the earth as a constituted whole shrinks the number of solutions we allow ourselves to explore: It limits our ability to account for the material and relational spatialities that help to harness and scale up energy resources (23), (24). For this reason, it is urgent that ways be found to acknowledge the diverse ways of scaling up that current processes of energy change follow and to jointly analyse their spatial and political dimensions.

Current debates about the Anthropocene offer stimulating perspectives to proceed in this direction. In his recent discussion of James Lovelock's notion of 'Gaia' (20), Bruno Latour invites us to go beyond the idea of the earth as a globe. The globe, so the author's argument goes, refers to a pre-existing totality, a bounded system made up of interactions between man and nature. Such a vague appreciation of the earth as a super-organism, however, is a too cursory a metaphor and unduly encapsulates the diversity of the living into a single stabilised entity. By suggesting that humans and non-humans are unified by such a bounded system, it paves the way for a modernist approach to science and its instrumentalist avatar - such as the current re-engineering strategies as an answer to climate change $(25)$. It falls short of addressing the 'global' issue of climate change, defined as how we might succeed in becoming assembled together around such an issue, and which type of global assemblage might result from it. In Latour's mind, the notion of Gaia makes it possible to reintroduce the Earth as an unpredictable stage for connecting things: "Gaia is not at all a Sphere. Gaia is a very thin membrane, no larger than a few kilometres, that delicately envelops the critical zones" . In defining Gaia as a delicately enveloping membrane, Bruno Latour foregrounds the fragile skin of the planet. He also points out the tight relation to life and the biosphere, as well as our critical responsibility in assembling the scale of the problem. In referring to the notion of "critical zone" - a notion that originated in earth science (26) - and in defining it as a "spot on the envelope of the biosphere" (21), he brings our responsibility into spatiality and motion: He gives it a stage, a relational setting. The critical zone goes from the outer extent of vegetation down to the lower limits of groundwater. It extends vertically (from the lower atmosphere to sterile rocks) and horizontally (with fluxes and relations) but does not have any particular size. Contrary to the idea conveyed by the notions of land, it cannot belong to a single interest nor be legally bounded as a territory.

We are here particularly interested in what is "critical" in the critical zone. Criticality first refers to environments that may break down entirely, shift from one state to another and confront us with unstable processes and unforeseen, mixed issues. Criticality also calls for reorganising scientific practices in order to account for the ontological changes at work in such processes. Ontological changes here points to the fact that the processes of energy change, including those of harnessing new and diffuse energies, interfere with environmental entities, enact 
them in multiple ways along unexpected spatialities and confers new properties and new capacities on them (e.g. (27), (28), (29)). As Latour puts it, attending to scientists through the lens of the critical zone turns them into members of a new geopolitics - i.e. a politics of multiple worlds making up a critical zone.

For us, the value of this approach lies in reintroducing the idea of a geographical space that is not bounded but constantly revised and resized through new technological developments (30), a point that has also been underlined in relation to energy change processes (31), (32), (33). Different from a constituted and stable globe, with the critical zone, the geographical space is made politically negotiable through specific spatial and sociotechnical assemblages. Fluxes and relations that crisscross the zone are potential lines and forks along which the earth can be assembled as an issue (e.g. for instance, our introductory example suggests that the transport of sediments, the migration of fish and the traditional fishing routes in the Channel are lines with which a large scale offshore wind power farm has to deal with to be settled in a way that pay attention to earth forces). As a spot (on the earth), the critical zone is a site of particular intensities: intensities of issues (because of its ties, it points to more than its own theatre, towards geopolitics; because of its assemblage, it sets us up as critical actors) and intensities of becoming (it involves more than itself and has no definite state or future). Notwithstanding this great analytical potential, the notion remains imprecise when it comes to following the ways in which the spatial dynamics that unfold in the zone have to be entangled on larger scales. This is especially an issue for us, who are interested in specifying the distinct and different spatial and relational ways in which new energy technologies and resources can be scaled up - e.g., how they might leave a point and travel from point to point on the membrane.

In order to bridge the gap, this paper takes inspiration from the work of Gilbert Simondon regarding the genesis of the technical object. Simondon holds that the technology does not exist separately from its environment but gradually becomes more efficient as it produces its own (associated) milieu. This well-known thesis is underpinned by a less-noticed development from the author with regard to the roles and types of spatial mediation that intervene in the broad distribution of technical objects. Simondon makes a distinction between two types of 'mediations': the ones that actively participate in the shaping of technical objects and the ones that underpin their gradual ordering and standardisation to allow for their widespread diffusion (i.e. their "scaling up").

Simondon notes that, among the diversity of places on earth, some are unique in that they gather a great range of forces, such as, in the field of renewable energy, the highest wind spots or the bays with the strongest tidal currents. If we engage in their exploration, these places will provide us with a new point of view on the forces at work and the way in which they are intertwined with other human and non-human entities. These places, which Simondon calls haut-lieux(here translated as 'intensive sites'), have a distinct capacity to foster intense 
relations with and among these forces and to make man more aware of the processes of technological emergence (seen as an object-milieu co-emergence). Stated differently, for our purposes, intensive sites are sites where the emergence of a technical object has a relationship with a geopolitics of the earth. Simondon is imbued inspired with the force of these sites. He insists that 'intensive sites' impose their force on humans: They are not explored 'to be dominated or owned, but to generate a situation of apprenticeship'. Thus, engineers and investors strategically seek out such privileged places for their potential to sustain the emergence of unprecedented relational patterns (Simondon speaks of a 'reticulation') between an (embryonic) technology and the geographical milieu and its forces and scales. Such 'intensive sites' are strategic to the current development of renewable energy technologies.

Simondon underscores the idea that the technical object, when it becomes stabilised and ready for developments in other places, loses its intimate relationship with an intensive site. In the process, the former reticulation between the technical object and its environment is somewhat reduced to a set of discrete points, a set of standards that make it possible to maintain the object's stability while manipulating and displacing the object itself. The technical object is thus partly separated from the world around it. It stays imperfectly related to it so as to travel and enter an extensive venture. In this respect, we suggest coining the term 'extensive site' as a complementary perspective on space to the former idea of 'intensive site'.

As rich as these two notions - intensive site (reticulation) and extensive site (standardisation) - are when it comes to reflecting on the emergence and widespread application of new technologies, they do not fully address the processes of scaling up that we are interested in exploring in a relational and spatial manner in this paper. While Simondon's account is detailed with regard to the processes of reticulation, it remains quite vague with respect to exploring the way in which the technical object is replicated and developed by extensive sites. And yet, the diffusion of technologies through extensive sites raises new political issues on a different scale because large-scale phenomena (e.g. migratory birds passing through large wind farms) are affected in this widespread development. Such issues are often handled through governmentality - as discussed by Michel Foucault (34) - by aggregating individuals into a "population" that is governed at a distance, a process that is very different from managing singular impacts on distinct individuals, which can happen at intensive sites.

However, objects that emerge at 'intensive sites' and pass to 'extensive sites' when deployed sometimes generate new intensive issues on new scales. Simondon's account thus invites us to carry it farther, which means bringing together and jointly analysing the various (intensive and extensive) spatialities that underpin the relationship between the technical object and its milieu. 


\section{Renewable energy projects coping with earth's untamed intensities: following}

\section{energy spatialities in the making}

The geographical expansion of renewable energies is studied through the prism of two 'critical' wind power projects: One was an attempt to develop a large-scale offshore wind power farm in the English Channel; the other was aimed at repowering and expanding an onshore wind power farm in an international migratory corridor in Southern France.

These fieldworks are based on written documents, graphics, participant observation and qualitative face-to-face interviews with ministry officials (e.g. environment, public works, industry and energy), local mayors, pro- and anti-'wind' NGOs, territorial organisations, wind power developers, private landscape firms and environmental experts engaged in developing wind power projects. The interviews were conducted in seven waves during spring 2008 and autumn 2009 for the offshore wind power project (28 interviews), and two waves during autumn 2006 and spring 2007 for the onshore wind power project (28 interviews).

\subsection{Moving forward offshore, exploring earth's intensities}

The emergence of offshore wind power development in Europe has been analysed in three steps (35), (36): (i) an experimentation phase (1991-2001) that aimed to test onshore marine turbines in shallow water (at a depth of about 4-6 m) near the shore (3-4 km away); (ii) a market adaptation phase (2002-2008), during which the first projects larger than $100 \mathrm{MW}$ appeared in the North Sea (10-30 km, 10-20 m in depth); and (iii) a market stabilisation phase (since 2009) characterised by very large commercial farms with several hundred MW and the predominant use of turbines with monopile foundations. Within this European context, the French case is not one of the most innovative, as the first national tender launched in 2004 ended in failure ten years later. Nevertheless, analysing this case study proves fruitful if we view this first experience in the framework of the ensuing and successive attempts in France to open the sea to offshore wind power. Indeed, the stalling of this first project did not stop the French state's attempts to develop wind power. From 2009 onwards, the French state reoriented its offshore wind power policy to account for the difficulties experienced at this first site. We focus our analysis on three processes: how the German offshore wind power experience influenced the emergence of the first French pilot project, how this French pilot project struggled with 'intensive spatialities' on its own site and how the French offshore wind power policy improved thanks to this first experience by adopting an 'extensive' marine strategy.

In 2002, the German federal government adopted a strategy to expand offshore wind power (37). This strategy consisted in developing a few pilot wind farms from 2003 to 2007 before entering into a series of expansion phases aimed at first installing 2000-3000 MW (2007-2010) and then continuing with additional capacities (2011-2030). The implementation 
of Germany's strategy started with the erection of research platforms in the North Sea (FINO I, II, III) to learn from pilot sites and share these findings with scientists and developers before embarking on very large projects. This case started with the approval of a pilot wind power site named "Borkum-West" (located in Borkum), which PROKON Nord Gmbh had been put in charge of in 1999. Borkum-West aimed to test the development of 12 wind turbines in the North Sea before developing a bigger, 1-GW wind farm.

By that time, in France, diverging strategies were under debate within the government. The General Secretariat for the Sea (SGMER, an administrative service in charge of advising the prime minister about maritime issues) advocated for a strategic marine plan to be devised that would identify offshore areas favourable to wind power development. For a variety of reasons, including pressure from the wind power developers lobby, which felt ready to experiment with offshore developments, the Ministry for the Economy bypassed the SGMER's proposal and launched a national call for a tender (in 2004). The call was supposed to lay the groundwork for the development of the first offshore wind farm on the French coast. In 2005, it resulted in the selection of the first French offshore wind power project: Veulettes-sur-Mer, supported by the French subsidiary of the German wind power developer Enertrag. As France's government had not devised any spatial planning, it was each developer's responsibility to propose a site, a technology and a price per $\mathrm{kW} \mathrm{h}$. This generated great uncertainty for petitioners with regard to how to select the most suitable site, technology and business model.

As a company jointly funded by PROKON Nord (28\%) and UCKERWERK Energietechnik GmbH (72\%), Enertrag sought in part to take advantage of its close financial, industrial and knowledge ties to Germany during this process. PROKON Nord's "(u)nmatched know-how for the design and development of offshore projects"(38) was highlighted in Enertrag's application and considered a precious advantage. Indeed, at the time, PROKON Nord was famous for its involvement in the development of deep-water wind turbines at Borkhum-West, $45 \mathrm{~km}$ offshore (at a depth of $30 \mathrm{~m}$ ). The firm intended to test its own new technology, the Multibrid $\mathrm{M} 5000$, a machine "dedicated to offshore (and) designed to work in saline and corrosive conditions". 4 The environment of Veulettes-sur-Mer in the English Channel suited the Multibrid M5000 very well, as the water is about 25-30 m deep.

In Germany, the North Sea had gradually been turned into an 'intensive site' following the erection of the FINO platforms: FINO I (in 2002), FINO II (in 2007 in the Baltic Sea) and FINO III (in 2009). The intention was to learn about the effects of wind power on marine mammals, seabirds, bird migration, the fauna of the seabed and fish (39), (40). In June 2006, a cluster of German energy companies 5 agreed to turn the site of Borkum-West into a shared test field named Alpha Ventus. With six M5000 turbines erected in 2009, Alpha Ventus became an 'intensive site' that supported the expansion of offshore wind power in the German North Sea. In France, where no offshore research platform was in place, the process of clearing the 
risks proved chaotic, as the director of Enertrag recounts: "FINO I, I've been there. This is a wonderful laboratory, located in the sea $45 \mathrm{~km}$ to the north of Borkum. It is funded at the federal level, and it does research on waves, tidal currents, wind speeds, birds etc. Many scientists and developers benefit from the results obtained there. Well, here in Veulettes, I have to do all this at my own expense." $\underline{6}$

Although inspired by the German offshore advances, the French project of Veulettes-sur-Mer could not really be regarded as an extension of the North Sea experience. Moreover, as an 'intensive site', it did not have a convincing start, as witnessed by the local state representative in charge of the administrative process: 'This is a real mess; no one understands anything!" $\geq$ The French learning-by-doing strategy had progressively become a stop-and-go process beset by many difficulties. First, the absence of a legal framework to authorise immobile infrastructures in the sea led the marine and terrestrial administrative services to combine their procedures. For the former, the sea was a vertical space (surface, mid-water, seabed); for the latter, the seabed was only the continuation of terrestrial land. Enertrag was then supposed to obtain authorisation to create its wind farm in the public maritime domain (marine services), a building permit for the turbines in the sea (terrestrial service), authorisation to put electric cables into the seashore (terrestrial service) and a declaration of public utility to connect the project to the grid (national grid manager). "This is a legal brainteaser", sighed a local state representative in charge of urbanism. $\frac{8}{\text { Each }}$ procedure sparked intense controversy within the administration, including what exactly should be considered offshore or onshore, to which seashore municipality the project should be submitted for administrative application, how far into the country the local population should be consulted etc. The project also triggered local and national opposition forces that attacked the building permit delivered in 2008 until it was cleared of any claims in 2013. While the frontiers between land and sea were constantly being debated, the project struggled more and more with "intensities" from the earth. By the end of 2005, the developer commissioned a geophysical prospection campaign to define a roughly homogeneous area in which to anchor the turbines. Their alignment was slightly changed to avoid a geological fault. In 2006, a barge came onsite to undertake geotechnical work and specify which type of foundations would be most appropriate for the turbines. "The barge was supposed to sink its eight legs into the ground, work freely out from the swell... but they never met the ground, they sank in a dozen metres of white chalk!" "While many offshore projects in the North Sea were based on gravel sand suitable for monopile foundations, the white chalk required tripod foundations and piles about $60 \mathrm{~m}$ in length to a layer of rock. This significantly increased the overall cost of the project and weakened its viability. Enertrag also had a test of strength with fishermen, who were worried about the degradation of marine habitats, the banning of fishing in the wind farm and the effects of electromagnetic fields on fish. This last point was a major concern among the locals. Fishermen had already seen shoals of fish splitting up when crossing an 
electrical or a phone cable. "We used to track shoals of fish along the channel. After a cable, the sonar shows us that the shoal cracked and takes a long time to reconstitute itself and be catchable with our fishing nets - sometimes 4 or 5 miles. "10 Enertrag was tasked with carrying out a study specifically focused on this problem to determine the impact of the offshore electric cables on the fish and evaluate the shortfall for local fishermen.

These challenges bring our attention to the fact that anchoring the turbines in the channel triggered relational issues that made earth matter. From nearshore to offshore, private developers go deeper into the water and explore geologically poorly known areas. According to the developer, "one of the key pieces of feedback"11 from this experience is that the site of Veulettes-sur-Mer introduced unexpected geological complexities (or 'intensities'), which led to more costly geotechnical studies and required oversized foundations. These additional costs, as well as the purchase of the foundations, the cables, the electrical substation and the first turbines before getting all the administrative authorisations - something "never done in the sector" - "contributed to the failure of PROKON Nord, which had injected its own capital".12 In France, this triggered a political debate about the inadequacy of the French national framework to select the offshore wind power zones and the administrative procedures that take too long. Anchoring the turbines also raised issues as to the potential interference between the electrical magnetic field (from grid-connection cables passing under the water) and the earth's electromagnetic field with the potential consequences of these interferences on fish circulation and spatialities, which in turn could affect the skills relationship of capture developed by fishermen to capture fishes in the Channel. This gave rise to a negotiated process. Fishermen asked Enertrag to co-lead an environmental impact study with marine scientists. They also required that scientists use local fishing boats and techniques in order to have a realistic assessment of the impact of the project in and around the wind farm area.

In 2007, newly elected President Sarkozy launched a national political forum, the Grenelle Environment Forum, aimed at devising French environmental policies (in a broad sense, energy, climate, agriculture, biodiversity, environment) through multi-stakeholder debates.

The process continued for three years until the legislative implementation phase in 2009 and 2010. This offered an opportunity to learn from the failure of Veulettes-sur-Mer, to restart a jammed national policy and to devise one that would fit a changing industrial sector (concentrations). As a pioneer, the director of Enertrag was leading the coalition of private offshore developers; he worked directly with the State Department of Climate and Energy to design a new framework. After the false start of the first French pilot site, the challenge was to adopt a national strategy that would span the different seafronts (English Channel, Atlantic Ocean, Mediterranean Sea). French and foreign wind power companies lobbied intensely to have the French government produce a new vision that would open an 'extensive space' (our wording) to large-scale offshore wind power development. Many changes were adopted by 
the law (Grenelle 2): the removal of terrestrial authorisations in sea space, an elaboration of marine strategic planning with pre-identified zones, as well as concerted developments on and with each of the seafronts. The French government launched three successive rounds of tenders to allocate offshore wind power capacities. This strategically aimed at supporting the rise of French national champions (e.g. Areva, Alstom, EDF-Energies Nouvelles). This new framework allowed new offshore spatialities to emerge in different ways, including new coalitions between the industrial sector and local authorities supporting a regional development around offshore wind power projects (e.g. Fécamp) and intensive exploratory processes with fishermen before siting the turbines (e.g. Saint Brieuc). Unlike with Veulettessur-Mer, the process of clearing the risks was more progressive, albeit financially supported by the developer. This opens up new possibilities to collectively articulate the earth's intensities and related spatialities that emerged during the siting of the turbines.

\subsection{Intensifying bird migrations, relating wind power to the earth's extensities}

This second case study is a wind power repowering project located in the Narbonnaise Regional Natural Park in the Aude department - on the border between France and Spain and on the eastern side of the Pyrenees (27). As one of the windiest places in France, Narbonnaise attracted interest for wind power development early on. It had welcomed the first industrial wind power project in France in the early 1990s - a project that could then be considered for repowering (dismantling the wind farm in order to set a new one) 20 years later, in 2010. $\underline{.13}$ Neighbouring communities shared an interest in repowering this wind farm located on shared common land, which allowed them to share part of the revenues from the wind farm (taxes, land rents).

Importantly, as a windy place, the small littoral plain of Narbonnaise is also on one of two migratory routes for birds on their way between Africa and Eastern Europe. Narbonnaise has a long and strong political history of bird watching. In the 1970s, it was one of the most important places in France where birdwatchers met and set up 'migration camps' to draw Europe's and the French government's attention to the need for regulatory protection. Migration camps were notably politicising birds by counting the population of birds passing over. According to birdwatchers, migration in Narbonnaise is quantitatively impressive. 14 It is also a rough experience for the birds. Migrating corridors are mostly used by soaring (or gliding) birds, such as black storks and big raptors, and they avoid situations in which rising air currents (updrafts, thermals) are absent, which is precisely the case over water areas (sea surface, lakes). Their margin for manoeuvre during their journey through Narbonnaise thus depends on the way the wind is blowing, and especially on whether the wind pushes them over the land and the hills (easterly wind or 'Marin'; loose corridor, easy migration) or onto the seashore and the waters (north-westerly wind or 'Tramontagne'; corridor restricted to the coastline, tough migration). 
As an area that channels both the winds and bird migration, Narbonnaise features a particular concentration of issues around wind power development, all of which are more or less directly connected with earth scale (bird migration) and politics (bird protection, climate protection). These interfere in and around the harnessing of wind, somewhat intensifying environmental issues and calling on extended scales of interactions and governance. In looking at this case study, we would like to foreground the interplay between extensive and intensive logics around issues at the crossroads between bird migration and protection, and wind power development.

We do so by focusing on two dimensions of this case study: 1) the way in which bird migration is intensively woven together with wind power around the siting of this project and leads to redefinitions of birds' cognitive and strategic abilities and protection, and 2 ) the way in which such redefinitions are processed and scaled up by France's League for the Protection of Birds (LPO) and feed into extensive processes sustaining the development of bird-compatible wind power projects on a national and European level.

\subsubsection{Intensive wind power spatiality for extended migrations (intensifying compatibilities)}

As for the first dimension, the location of the Plateau de Garrigue Haute (the wind power site) within a major migration corridor logically made birds an important project adjuster. The project design and siting proposal involved collaboration between the wind power developer and the local branch of the LPO. Part of the benefits was to be shared with local actors - the LPO, a local hunters' NGO and a local shepherd, all of them already involved in an EU Life Project - in order to allow for environmental compensation and for the monitoring of the impact of the future wind farm on migrating birds.

As a collaboration between a developer and bird watchers, the project design triggered an experimentation. The LPO developed a new method for observing birds. "Micro-siting", as this method is called, focuses on the way in which birds use a site, including the wind and the (potential) presence of wind turbines. Unlike usual birdwatching methods in the Narbonnaise area, micro-siting is neither a census nor primarily about counting the size of the migrating species populations. It is about following individual birds in order to understand the way in which they develop strategies in relation to the presence of wind turbines. Birds could "fly over" the turbines, they could "dive in" (fly through, below the blades), or they could "make their way east" or "west". Thus, it is about individual stories, individual or small group successes, difficulties and failures in passing through, alongside or over a wind farm. It is about birds' strategies to find thermals and updrafts, about soaring and gliding. Observations in relation to topography clearly provided a fine-grained understanding of birds' reactions to the site. 
Focusing on spatialised individual stories allows micro-siting to capture birds' intelligence. It also reshuffles bird categories, as some passerines prove to be as skilled as some raptors. Additionally, the significant number of observations that were undertaken allowed the survey to use genuine statistical methods and to translate individual/small group reactions into family/species behaviours. As these were associated with distinct spatialities, they allowed for the delineation of "micro-flying ways" - a fine-grained and spatially differentiated representation of the migration flow at the level of the site. "Micro-flying ways" were then used in collaboration with the wind power developer to design a siting that would be compatible with bird migration.

Such a spatialised account endowed birds with new capacities and developed the politics of bird protection in that same area where migration camps had politicised it in the 1970s. Importantly, it showed that developing wind power implied sharing wind (energy) between birds and humans, a reformulation that paved the way for compatibilities - as compared with the "bird chopper" imagery conveyed by wind power opponents at that time - while anchoring such compatibilities in a localised and spatial account: It made it conditional upon siting (only micro-siting could make sharing tangible). Such a conclusion, embedded in the site where it was produced, required re-examination if it was to be exported to any other site.

\subsubsection{Extensive wind power politics for intense bird migrations (extensifying compatibilities} Since the mid-1990s, the French LPO has been concerned with wind power development and policy and reflected on how to evolve its politics in relation to these issues. The Aude branch of the LPO was one of the first local branches to face rapid wind power expansion and to warn the national LPO while also seeking support. Surveys undertaken at the Plateau de Garrigue Haute (in 1997 and 2001) were benchmark experiences in this process, partly grounding a 2002 national LPO position statement that was favourable to wind power, provided that its development be undertaken in accordance with biodiversity issues. The national LPO also decided to become proactive in planning and helping the administration, private developers and other environmental NGOs to grasp the wind power issue. This translated into a full range of actions, including a collaboration with the national and local administration in assessing wind power projects and developing new bird watching methods (e.g. micro-siting).

LPO engagement in wind power planning hinged upon a few principles that included: 'anticipatory planning' (collaboration with local administrations and PNRs in devising planning schemes), 'pre-diagnosis' (in-house mapping, informing territorial and planning intelligence) allowing for early LPO position on project development, as well as 'monitoring and lawsuits' (suing borderline projects in the administrative court to stop them). These principles integrated micro-siting with planning and political action on different scales, allowing this innovation to go beyond siting without losing its connection to the site. 
The full process by which this was achieved cannot be detailed here (for more details, see (27)). What matters is that by doing so, the LPO managed to weave together intensive processes of articulation between wind power development and bird presence with extensive processes of channelling and diffusing of a type of wind power that was thought compatible with the protection of biodiversity. Eventually, the experimentation of the French LPO made its way to the European bird watching network (41).

Following Rodriguez-Girlat, we can say that the bird-LPO joint action in this case study enacted political lines (29) that connected located/troubled ontologies (birds are successively processed as skilled beings, individual trajectories, statistical indicators, spatial intensities, micro-migrating corridors) with the politics of a broader scale to turn the repowering on the Plateau de Garrigue Haute into a stage for earth politics.

\section{Exploring the 'critical zone': conceptual strategies for navigating the geo- political spatialities of energy}

One aim of this paper was to acknowledge that issues associated with the spatial deployment of renewable energies cannot be reduced to quantification or spatial metrics. Another was to engage with a qualitative, spatial and political appraisal of these changes. We assumed that such an appraisal could be achieved by following the deployment of large-scale renewable energy projects because the developments of these projects, as they struggle with a broad range of forces (geological, animal, etc.) in the largely unknown environments (underground, offshore, aerial, etc.) in which they are settled, offer an occasion to observe the emergence of earth's politics.

In operationalising this relational perspective, we relied on the notion of a critical zone (borrowed from Bruno Latour) because it allowed for a dynamic, relational appraisal of the spaces in which renewable energies are deployed, an appraisal that circumscribes neither the environment nor the technology and leaves open for inquiry the dimensions of the earth's crisis that emerge in the making of situated entanglements. The notions of 'intensive' and 'extensive' sites, inspired by Simondon's approach to technology, allow us to specify in greater detail the processes through which intense earth forces (the untamed Gaia) underpin such technological experiments, as well as their extensive diffusion and scaling up.

Two critical sites and projects opened up to earth's forces. The offshore wind power project of Veulettes-sur-Mer proved to be 'critical' because, unlike other European countries that learned from previous near-shore single-turbine projects, France started its offshore development with a large, deep-water, multi-turbine project and in the absence of experience with its own marine environment. The onshore wind power project of Narbonnaise was 'critical' because it engaged with the repowering of a wind farm in a major European migratory 
corridor. These untamed environments called for articulating extensive logics (offshore wind power development patterns in the North Sea, bird migration, bird watching methodology diffusion) with learning from singular intensities (strong marine currents, coastal fish highways, moving seabed, narrow coastal passage, large bird migrations...) in order to stabilise energy technologies.

\section{1. 'Intensive' and 'extensive' sites: a critical appraisal of Simondon's notions}

Our case studies invite us to challenge and sharpen the meaning of a pair of notions: 'intensive' and 'extensive' sites. Simondon insists on the difference between places of a high relational intensity, which we translated as 'intensive site', in which technological prototypes are run for the first time, and places of low relational intensity ('extensive sites'), in which mature technologies can be deployed on a large scale. Our case studies display different articulations between intensive and extensive spatialities that are worth pointing out. A first configuration, briefly mentioned above, suggests that an intensive site (the Alpha Ventus pilot wind farm in the North Sea) can play a strategic role as a spatial mediation between intensive development (on this pilot) and extensive deployment in the same environment as the pilot (the North Sea). A second configuration shows that a supposedly extensive site (Veulettessur-Mer as a replication of the Alpha Ventus model, or Narbonnaise as an extension of onshore wind power development in France) can set the stage for earth's intensities and engage humans and non-humans in an intense relational and exploratory work.

Furthermore, the contrasting outcomes of this second configuration raise issues regarding the role of spatial mediations when it comes to engaging with earth's politics. In the offshore case study, the offshore potential defined by the tender as a combination of as a site/technology/ price-per-kW $\mathrm{h}$ fails to be articulated with marine intensities as they continually call for a rescaling of the project (seabed, marine currents, seafront). By contrast, in Narbonnaise, where the extension of the onshore potential in a migratory corridor could have been regarded as too risky a plan, carefully following the migratory lines takes advantage of intensities and eventually succeeds in devising a sharing of the wind that suits all parties. Such differences in one and the same configuration challenge the capacity of Simondon's notions to capture significant differences in the dynamics of spatial relations.

One limitation of Simondon's account lies in the role conferred on extensive sites. These sites play a minor role, mostly as passive receptacles of technology. Technology is cast as a relational and dynamic entity that is progressively fragmented, simplified and standardised in order to circulate from site to site, and it is diffuse. Thus, it plays the strategic role of mediating the relationships between man and his environment. By contrast, our case studies shed a more complex but also more generous light on the role of extensive sites. The Narbonnaise case study, for instance, demonstrates that a place that was formerly organised around earth's intensities and politics (bird migration and protection) can play an active role in steering the 
geographical diffusion of new energy technologies. This should not surprise us: If space is relational, its socio-material construction (the constitution of a bird watching networks, of a local political culture around migrations flows) should matter when it comes to how much technological development it can sustain. Moreover, as shown by the Veulettes-sur-Mer case study, the historical construction of space (the administration's partition of the earth's surface, such as the separation between land planning and sea-space regulation) may hamper the passage from the extensive (transferring of a model of development coming for the North Sea) to the intensive (the site of Veulettes-sur-Mer).

Thus, 'intensive' and 'extensive' sites are not to be opposed to each other, nor are they chained together in a linear manner. Extensive sites can sustain intense relational work. They do not differ from intensive sites by their relational intensity (high intensive sites or low for extensive) but by the spatial scales on which their intensities arise - a point we examine below.

\subsection{Scaling up and the spatial quality of extension}

Our initial concern with not reducing the spatial deployment of renewable energies to quantification or spatial metrics pointed to the possibility of having different paths to scale up new energy technologies. By suggesting that relational intensities are not the prerogative of intensive sites (welcoming a technology prototype), we suggest that there may be a distinct quality to the extensive deployment of energy technologies (through extensive sites) that has value for our qualitative (relational) appraisal of scaling up.

In his work on the evolution of biology at the beginning of the 20th century (42), (43), Kohler emphasises the decisive role that places' materiality play in allowing (or not) for the observation of critical relations in the ecosystems, in rendering them perceptible and in staging their political dimension. These relations, he argues, would not have come into existence without a spatial and material staging. Field biologists purposefully selected natural places that already offered distinctly favourable settings for listing, counting and weighing species. In other words, they were lab-like. They did not look for neutral places, nor did they work on transforming places or on eliminating elements to allow for observation. Biologists' approach was to have nature do the experimenting in a set of sites and for them to observe a phenomenon's progression, regularity or variability. Thus, the spatial quality of these 'labscapes' was not to be artificialised or bounded, as modern laboratories do, but to operate from nature and in a collective manner, as a 'border': Kohler coined the notion to emphasise the multisited and multidimensional character of this scientific endeavour, which underscored the diversity of earth's scales and forces.

Approaching energy spatialities as border-like entities makes it possible for us to stress that these spatialities are not reduced to spots, as the notion of a 'critical zone' might suggest, but partake in a pioneering, moving and dynamic fringe. In so doing, they bind intensive and 
extensive explorations together in a qualitative venture. Thus, there are multiple ways of confronting critical earth issues. On the one hand, our case studies clearly foreground the intense relational work that goes on at distinct sites and even suggests fleshing out the idea of a 'connection' between the earth's membrane and its critical zones, which Bruno Latour purposefully leaves unspecified (21). Latour insists that there is no world that is already common to begin with: A politics of the earth requires that we bring together the entities that are affected by the critical becoming of a 'zone'. Yet, the way in which these get "connected" to the earth's membrane in order to nurture geopolitics is not specified. Following Ingold, one could think of different pathways to become part of and engage with a critical zone. While Latour insists on the networking activity of the 'critical zonists', Ingold focuses on the 'meshwork' that living things develop when they compose their worlds: "The world, for me, is not an assemblage of heterogeneous bits and pieces but a tangle of threads and pathways. Let us call it a meshwork, so as to distinguish it from your network' (44:212). The meshwork is not a matter of connecting separate entities to develop an agency; it is a matter of becoming experienced and skilled by coupling the body with a material medium. However, Latour's and Ingold's relational approaches may be regarded as complementary in that they emphasise discontinuity (through instruments, monitoring, feedback loops, capacity of calculation...) and continuity (capturing forces along lines to live adequate experiences), respectively, in the work of relating with our environment. The notion of a 'critical zone' could thus be envisioned as pointing out a critical articulation between meshwork and network - of which that of indigenous/traditional and scientific knowledge is an instantiation. Instruments, monitoring and calculations are ways of following and connecting with lines of experiences in the environment. The sharing of wind energy in Narbonnaise shows that the 'criticality' of the migratory corridor is a matter of opening the territorial definition of this corridor (as a protected area) to the moving experience of migration. Looking at birds as 'lines' - i.e. living entities that are engaged in a long, enduring journey and part of a broader ecosystem that has to be protected - enables bird watchers to become critical zonists. They do not restrict their work to lab-type/onsite monitoring and calculation but relate this experience to the critical pulse of earthly bird migrations while keeping in mind the distant places to which the birds relate them.

On the other hand, extensive deployments confront us with the earth's critical dimensions along different qualitative lines: They multiply occurrences of confrontations, offering occasions to compare and compose on a new scale and with different intensities. This can be through the extension of projects, such as the repowering of a wind farm, which might impact a local environment in such a way that they overflow it: In Narbonnaise, LPO refused to renew its collaboration with wind power developers in the migratory corridor, arguing that the pressure for wind power development was so intense that it would then have an impact on bird migration. This can also be through the extensive deployment of technology at new sites. 
For instance, wind power development in France triggered the undertaking of so many impact studies that it provided the opportunity to match and map bird migratory routes on an unprecedented scale. Extensive sites can bring their own qualitative insight for our understanding of processes of scaling up, either because they multiply occurrences of relations or because they overflow and saturate existing environments. By taking advantage of these different relational strategies, we can follow emerging energy spatialities and question their closing/opening, networking/weaving with the earth's membrane.

\section{Conclusion}

A striking aspect of the current energy transition is the rapid deployment of renewable energy technologies on the earth surface to harness diffuse and scattered energy resources (wind, sun, tides, biomass...). This energy sprawl has major consequences on the existing land patterns and the ecosystems. An increasing number of works acknowledges this land rush from a quantitative perspective. While useful, this paper - after others, see for instance Smil (4) - assumes that land cover cannot be measured simply by adding up the areas which use has been affected by the spatial expansion of renewable energy technologies. Specific relational issues are raised by the expansion and the scaling up of these new energy technologies in a variety of geographical environments (offshore, onshore, underground, aerial), and call for an alternative and more qualitative approach.

In order to do so we have proposed to articulate Simondon's spatial approach to the emergence of technological objects ('intensive' - 'extensive' sites) with Bruno Latour's approach to the politics of Gaïa (through the notion of 'critical zone'). Our case studies have fleshed out how the spatial expansion of renewable energy technologies makes earth matters in the sense that it could affect and interfere with polymorphous earth intensities (e.g. strong marine currents, coastal fish highways, moving seabed, narrow coastal passage, large bird migrations...). These ones are entangled in moving media (wind, sea) that connect energy projects to other places and interests. In such a situation, a more clearly defined view of the energy sprawl cannot only rely on the accurate calculation of the total land covered by renewable energy technologies. It also calls for a qualitative assessment about how ecosystems are being fragmented by these technological developments and the living entities attached to them interrupted in their routes.

Our case studies have also pointed out the fact that these earth forces when observed, monitored and discussed could open the way to local experiments that provide them with a new relational existence and a new political status (e.g. the attention paid to the relationship between fish and fishermen in the Channel, or between birds and wind turbines in the migratory corridor of Narbonnaise). At last, these new geo-political entities and the innovative knowledge attached to them have a capacity to circulate from their intensive site to different 
political scenes where to inform public policy frameworks (e.g. the revised French offshore wind power policy) or the political stance of international NGO (e.g. the position of Birdlife international about wind power).

Finally, applying this notional articulation (Simondon/Latour) to two case studies leads us to challenge Simondon's approach to the extensive diffusion of technological objects and to emphasize that intensive relational work could as well underpin the diffusion of technological objects. It also expanded Bruno Latour's notion of critical zone in pointing out the meshwork of renewable energy project development, a work that contributes in relating the projects scene with its broader large scale environment. This in turn opened to a more qualitative appraisal of processes of large scale diffusion of new energy technologies, in which such processes are recognised their own, collective and 'border-like', way of confronting what we called earth's forces or matters. This ultimately invites us to explore further the distinct spatialities of new energy development, the differences between intensive and extensive processes as well as their relational interweaving.

\section{Acknowledgements}

The authors extend their sincere gratitude to Vanesa Castan Broto for inviting them to the Cumberland Lodge seminar in May 2016, where they presented and collectively discussed a preliminary version of this paper. They are also grateful to the three anonymous reviewers for their comments and suggestions.

\section{References}

(1) NASA, Earth Observatory, comments about satellite images obtained on 30 June 2015. https://earthobservatory.nasa.gov/IOTD/view.php?id=\%E2\%80\%8C89063. (Accessed 7 September 2017).

(2 ) D. Howard, R. Wadsworth, J. Whitaker, N. Hugues, R. Bunce The impact of sustainable energy production on land use in Britain through to 2050 Land Use Policy, 26 (2009), pp. 284-292

(3 ) D. Konadu, Z. Sobral Mourao, J. Allwood, K. Richards, G. Kopec, R. McMahon, R. Fenner Land use implications of future energy system trajectories-the case of the UK 2050 Carbon Plan Energy Policy, 86 (2015), pp. 328-337

(4) A. Trainor, R. McDonald, J. Fargione Energy sprawl is the largest driver of land use change in United States PLoS One, 11 (9) (2016), pp. 1-16

(5 ) R. Hernandez, S. Easter, M. Murphy-Mariscal, F. Maestre, M. Tavassoli, E. Allen, C. Barrows, J. Belnap, R. Ochoa-Hueso, S. Ravi, M. Allen Environmental impacts of utility-scale solar energy Renew. Sustain. Energy Rev., 29 (2014) (2014), pp. 766-779

(6) J. Waite Land reuse in support of renewable energy development Land Use Policy, 66 (2017), pp. 105-110 
(7) G. Walker Energy, land use and renewables. A changing agenda Land Use Policy, 12 (1995), pp. 36

(8) V. Smil World history and energy C. Cleveland (Ed.), Encyclopedia of Energy, vol. 6 (2004), pp. 549-561

(9) V. Smil Energy in Nature and Society. General Energetics of Complex Systems MIT Press, Cambridge (2008)

(10) A. Scheidel, A. Sorman Energy transitions and the global land rush: ultimate drivers and persistent consequences Global Environ. Change, 22 (2012), pp. 588-595

(11) N. Thrift Environ. Plann. D: Soc. Space, 18 (2000), pp. 213-255

(12 ) S. Whatmore Hybrid Geographies Sage, London (2002)

(13) D. Massey For Space Sage, London (2005)

(14) J. Murdoch Post-structuralist Geographies Sage, London (2006)

(15) M. Akrich La construction d'un système sociotechnique. Esquisse pour une anthropologie des techniques Anthropologie et Sociétés, 13 (1989), pp. 31-51

(16) M. Akrich Les formes de la médiation technique Réseaux, 60 (1993), pp. 87-98

(17) M. De Laet, A. Mol The Zimbabwe bush pump: mechanics of a fluid technology Soc. Stud. Sci., 30 (2000), pp. 225-263

(18) J. Law, A. Mol Situating technoscience: an inquiry into spatialities Environ. Plann. D: Soc. Space, 19 (2001), pp. 609-621

(19) G. Simondon Du mode d'existence des objets techniques Aubier, Paris (1989) (ed. orig. 1958)

(20) B. Latour Face à Gaïa Huit conférences sur le nouveau régime climatique La Découverte, Paris (2015)

(21) B. Latour Some advantages of the notion of Critical Zone for Geopolitics Procedia Earth Planet. Sci., 10 (2014), pp. 3-6

(22) R. O'Neill, A. Nadaï Risque et démonstration, la politique de capture et de stockage du Dioxyde de Carbone (CCS) dans l'Union Européenne Vertigo, 12 (2012)

(23) A. Nadaï Le temps des solutions: politique des échelles politique des potentiels La Lettre de I'INSHS, 38 (2015), pp. 30-31 View Record in Scopus

(24 ) A. Nadaï, O. Labussière Exhaustible-renewable wind power S. Bouzarofski, V. Castan Broto, M. Pasqualetti (Eds.), The Routledge Research Companion to Energy Geographies, Routledge (2017)

(25) D. Keith Geoengineering the climate: history and prospect Annu. Rev. Energy Environ., 25 (2000), pp. 245-284

(26) S. Brantley, T. White, A. White, D. Sparks, D. Richter, K. Pregitzer Frontiers in Exploration of the Critical Zone, Report of a Workshop National Science Foundation, Newark, DE (2006)

(27) A. Nadaï, O. Labussière Birds, turbines and the making of wind power landscape in South France (Aude) Landsc. Res., 35 (2010), pp. 209-233 
(28) A. Nadaï, O. Labussière Playing with the line, channelling multiplicity-wind power planning in the Narbonnaise (Aude, France) Environ. Plann. D, 31 (2013), pp. 116-139 View Record in Scopus

(29) I. Rodriguez-Girlat Birds as lines: the production of alternative regimes of environmental management in the aftermath of a toxic disaster Geoforum, 66 (2015), pp. 156-166

(30) N. Clark Politics of strata Theory, Culture and Society, Special Issue: Geosocial Formations and the Anthropocene (2016), pp. 1-21

(31 ) A. Nadaï, O. Labussière Landscape commons, following wind power fault lines: the case of Seine-et-Marne (France) Energy Policy, 109 (2017), pp. 807-816 Special Issue The collaborative making of energy landscape

(32) A. Nadaï, O. Labussière Recomposer la mer pour devenir offshore: le projet éolien de Veulettessur-Mer Nat. Sci. Soc., 22 (2014), pp. 204-218

(33) O. Labussière, A. Nadaï Unexpected wind power 'potentials': the art of planning with inherited socio-geographical configurations (France) Scott. Geogr. J., Special Issue: Geogr. Commun. Energy Futures: Altern. Res. Paths, 130 (2014), pp. 1-15

(34) M. Foucault Security, Territory, Population. Lectures at the College De France, 1977-78 Palgrave Macmillan (2009)

(35) S. Rodrigues, C. Restrepo, E. Kontos, R. Teixeira Pinto, P. Bauer Trends of offshore wind projects Renew. Sustain. Energy Rev., 49 (2015), pp. 1114-1135

(36) J. Gorenstein Dedecca, R. Hakoort, J. Roland Ortt Market strategies for offshore wind in Europe: a development and diffusion perspective Renew. Sustain. Energy Rev., 66 (2016), pp. 286-296

(37 ) E. Bruns, D. Ohlhorst, B. Wenzel, J. Köppel Renewable Energies in Germany's Electricity Market. A Biography of the Innovation Process Springer (2011)

(38) Enertrag, Projet éolien offshore "Côte d'Albâtre", 2004.

(39) BSH \& BMU Ecological Research at the Offshore Windfarm Alpha Ventus-Challenges, Results and Perspectives Federal Maritime and Hydrographic Agency (BSH), Federal Ministry for the Environment, Nature Conservation and Nuclear Safety (BMU), Springer Spektrum (2014)

(40) M. Durstewitz, B. Lange Sea-Wind-Power. Research at the First German Offshore Wind Farm Alpha Ventus Springer (2017)

(41) BirdLife International, Position statement on wind farms and birds. Adopted by the BirdLife Birds and Habitats Directive Task Force on 9 December 2005.

(42) R. Kolher Place and practice in field biology Hist. Sci., 40 (2002), pp. 189-210

(43) R. Kolher Labscapes: naturalizing the lab Hist. Sci., 40 (2002), pp. 473-501

(44) T. Ingold When ANT meets SPIDER: social theory for arthropods K. Carl, M. Lambros (Eds.), Material Agency: Towards a Non-anthropocentric Approach, Springer (2007), pp. 209-215

For instance, turbines' land use depends on the dimensions of their blades. At most, 20 turbines with blades $25 \mathrm{~m}$ in diameter can fit into an area of $1 \mathrm{~km}^{2}$. 
Power density is the power per unit of land area and is expressed in watts per square metre. It usefully fleshes out the claim for land that results from the progressive shift from fossil fuels' high power density to renewable energies' low power density.

This conference preceded the twenty-first session of the Conference of the Parties (COP) that had been held in Paris (July 2015).

$\underline{4}$

Interview by the authors with the project leader of Enertrag France, 11 June 2008.

EWE AG, E.ON Climate \& Renewables GmbH and Vattenfall Europe New Energy GmbH founded the "Deutsche Offshore Testfeld und Infrastruktur GmbH \& Co. KG (DOTI)".

Interview by the authors with the director of Enertrag France, 18 January 2008.

$\underline{7}$

Administrative Wind Power Committee at the Prefecture of Rouen, 5 May 2008.

$\underline{8}$ Interview with the local state representative in charge of Urbanism in Dieppe, 7 February 2008. Interview by the authors with the project leader of Enertrag France, 11 June 2008.

$\underline{10}$ Interview by the authors with the president of the regional committee for fishing activities in Haute Normandie, 7 February 2008.

$\underline{11}$ Interview by the authors with the project leader of Enertrag France, 11 June 2008.

$\underline{12}$ Interview by the authors with a former engineer at Enertrag France, 2 February 2014.

$\underline{13}$ Under the French feed-in tariff, wind power developers commonly consider 20 years as the time lag after which turbines can be dismantled and replaced. 
About 40,000 raptors (19 species), 1500 storks (two species) and 1,000,000 passerines pass through every year, making the area a unique place for bird watching in Europe. 